\title{
REVIEW
}

\section{Nocturnal leg cramps in older people}

\section{J V Butler, E C Mulkerrin, S T O'Keeffe}

Postgrad Med J 2002;78:596-598

Nocturnal leg cramps are common in older people. Such cramps are associated with many common diseases and medications. Physiological methods may be useful for preventing cramps in some people, but there have been no controlled trials of these approaches. Quinine is moderately effective in preventing nocturnal leg cramps. However, there are concerns about the risk/benefit ratio with this drug. In patients with severe symptoms, a trial of 4-6 weeks' treatment with quinine is probably still justified, but the efficacy of treatment should be monitored, for example using a sleep and cramp diary.

See end of article for authors' affiliations ......................

Correspondence to: Dr O'Keeffe, Unit 4, Merlin Park Regional Hospital, Galway, Ireland; sokanc@iolfree.ie

Submitted

2 November 2001

Accepted 15 May 2002
C ramps are episodes of pain, usually lasting up to a few minutes, caused by sudden, intense involuntary contractions of muscles or muscle groups. Residual discomfort and tenderness may persist for hours afterwards. Nocturnal leg cramps, usually involving the calf muscles or the small muscles of the foot, are common and troublesome in older people. In a general practice based study of 233 people aged 60 years or more, almost one third had had rest cramps during the previous two months, including one half of those aged 80 years or more. ${ }^{1}$ Furthermore, $40 \%$ of subjects had cramps more than three times a week, and $6 \%$ reported daily rest cramps. Another study of 350 elderly outpatients found that $50 \%$ had rest cramps, with $20 \%$ reporting symptoms for 10 years or more. ${ }^{2}$

Although cramps are generally a benign and transient problem, they can cause considerable distress for patients. Management can be difficult, and there has been considerable controversy about the safety and efficacy of quinine, which is widely used for this condition.

\section{PATHOPHYSIOLOGY}

The pathophysiology of muscle cramps is still uncertain. The "squatting" hypothesis suggests that the modern habit of sitting at rest or at toilet, rather than squatting like our ancestors, leads to muscle and tendon shortening and inadequate stretching and puts the individual at risk for developing leg cramps. ${ }^{3}$ Neurophysiological and electromyographic studies suggest that cramps result from spontaneous firing of groups of anterior horn cells followed by contraction of several motor units at rates of up to 300 per second. ${ }^{4}$ This is considerably more than occurs in voluntary muscle contraction. A distal origin in the intramuscular motor nerve terminals has been suggested. ${ }^{5}$ Mechanisms that may contribute to motor unit hyperactivity include spinal disinhibition, abnormal terminal motor nerve excitability, and enhanced muscle contraction propagation through cross activation of adjacent neurons. Pain may occur as a result of accumulation of metabolites or possibly as a result of focal ischaemia. Muscle cramps are a common consequence of unaccustomed vigorous exercise. Also, peripheral vascular disease is more common in patients with cramps than in matched patients without cramps. $^{26}$ Nevertheless, most nocturnal leg cramps occur independently of arterial circulation. $^{5}$

\section{AETIOLOGY}

Although nocturnal cramps are idiopathic in most people, a large number of potential aetiological factors have been reported. Medications that have been reported to cause leg cramps include diuretics, nifedepine, $\beta$-agonists, steroids, morphine, cimetidine, penicillamine, statins, and lithium. ${ }^{7-9}$ In one general practice based study, $53 \%$ of patients taking quinine for cramps were also taking one or more medications that potentially cause cramps. ${ }^{10}$ Medical conditions associated with muscle cramps include uraemia, diabetes, thyroid disease, hypomagnesaemia, hypocalcaemia, and hypokalaemia. Hence, it is sensible to check urea, creatinine, potassium, magnesium and calcium concentrations, random blood glucose, and thyroid function tests in patients with cramps.

\section{DIFFERENTIAL DIAGNOSIS}

The diagnosis of nocturnal leg cramps is based on a careful history and on the absence of physical signs or disease. Conditions that may mimic cramps includes simple muscle strain, dystonias, ischaemic or neuropathic claudication, nerve root disease, restless leg syndrome, and nocturnal myoclonus.

Muscle cramps are a feature of many myopathic and neuropathic conditions. Cramps due to myopathy or neuropathy diseases are not usually restricted to the nighttime or necessarily to the legs. Nevertheless, a careful examination of the neuromuscular system is essential in patients with troublesome cramps, and investigations such as creatine phosphokinase, aldolase, electromyography, and nerve conduction studies may be indicated in selected patients.

\section{TREATMENT}

A thorough explanation with emphasis on the benign nature of the condition is beneficial. Any disease that may precipitate cramps should be identified and treated. Cautious withdrawal or substitution of drugs known to cause cramps should be considered. Patients should be advised 
about general measures to improve sleep, such as not going to bed until sleepy, ensuring a comfortable environment for sleep, and avoidance of alcohol and caffeine-containing beverages before bed.

\section{PHYSIOLOGICAL MEASURES}

Physiological methods of terminating and preventing cramp deserve a therapeutic trial given that a completely safe and effective pharmacological remedy remains elusive.

Cramps can be aborted by making use of reciprocal inhibition reflexes, in which contracting a group of muscles forces relaxation of the antagonistic group. ${ }^{11}$ Hence, forcible dorsiflexion of the foot with the knee extended can relieve calf cramps. Passive stretch or massage of the affected muscle may also help.

Similar approaches have been recommended to prevent cramps, but controlled trials to establish their efficacy are lacking. In an uncontrolled study of 44 patients, passively stretching the calf muscles three times a day for several days successfully prevented cramp. ${ }^{12}$ Subjects stood three feet from a wall, leaning against it with arms outstretched and gently tilted forward with the heels kept firmly in contact with the floor until a non-painful stretch was felt in the calves. This position is held for 10 seconds and repeated after five second intervals three or four times. Raising the head of the bed and raising the feet on pillows have both been advocated; neither approach has been formally evaluated. ${ }^{313}$

\section{PHARMACOLOGICAL THERAPY}

Pharmacological treatment of leg cramps may be necessary when symptoms are frequent and severe and where the above measures have failed.

\section{Quinine}

Quinine, an alkaloid originally produced from the bark of the cinchona tree, reduces the excitability of the motor end plate to nerve stimulation and increases the refractory period of skeletal muscle contraction. ${ }^{14}$ It has been used to treat leg cramps since 1940, usually as quinine sulphate but sometimes as hydroquinine. ${ }^{15} 16$

Trials examining the efficacy of quinine in nocturnal leg cramps have produced conflicting findings. A meta-analysis of six randomised, double blind controlled trials concluded that 200-300 mg of quinine sulphate at night resulted in a significant reduction in the number of cramps for a four week period compared with placebo (8.8 fewer cramps; 95\% confidence interval (CI) 4.2 to 13.5). ${ }^{17}$ However, the results of a later meta-analysis by the same authors which included data from unpublished trials gave less impressive results; this study found that patients had 3.6 (95\% CI 2.2 to 5.1) fewer cramps in a four week period when taking quinine compared with placebo. ${ }^{18}$ Quinine did not produce a significant change in the severity or duration of individual nocturnal leg cramps, and beneficial effects were only apparent after four weeks of treatment. In a double blind, placebo controlled trial, a combination of quinine and theophylline led to greater decrease in cramp frequency than placebo or quinine alone. ${ }^{19}$

Because it has been widely used for so long, doctors may underestimate the side effects of quinine. In 1995, the USA Food and Drug Administration concluded that the risks of quinine outweighed any possible benefit and ordered a stop to the marketing of quinine for prevention or treatment of nocturnal leg cramps. ${ }^{20}$ The most serious complication of quinine use is development of potentially fatal hypersensitivity reaction, particularly quinine-induced thrombocytopenia. The Food and Drug Administration analysis of published and unpublished data suggested that thrombocytopenia affects between 1:1000 and 1:3500 users. ${ }^{21}$ There are no known factors that predispose people to the development of hypersensitivity to quinine, and it may occur after a single

\section{Key points}

- Troublesome nocturnal leg cramps are common in older people.

- Cramps are associated with many common diseases and medications.

- Physiological methods of preventing cramp have not been examined in controlled studies. Nevertheless, such methods deserve a therapeutic trial given that a completely safe and effective pharmacological remedy remains elusive.

- Quinine is moderately effective in preventing nocturnal leg cramps. However, there are significant concerns about the risk/benefit ratio with this drug.

- In patients with severe symptoms, a trial of 4-6 weeks treatment with quinine is probably still justified, but patients should be warned of the risks, and the efficacy of treatment should be monitored.

dose or after months or years of use. Other rare complications of quinine include pancytopenia, haemolytic uraemic syndrome, and hepatitis. 223

Warburton and colleagues noted a significant relationship between serum quinine concentrations and relief of leg cramps. ${ }^{13}$ However, toxic levels of quinine give rise to cinchonism, a condition manifested by tinnitus, visual disturbances, vertigo, nausea, vomiting, abdominal pain, and deafness. Severe toxicity can lead to permanent blindness, cardiac arrhythmias, or death. Chronic impairment of auditory, vestibular, and visual function have been reported even in subjects taking doses of 200 to $300 \mathrm{mg}$ daily. ${ }^{24}$ The frequency and severity of adverse effects may be greater in older people since altered pharmacokinetics with age results in a longer half life of quinine..$^{14}$ Furthermore, the effects of quinine will add to those of pre-existing sensory defects in older people, while the latter may mask early signs of quinine toxicity. Also, quinine interacts with several widely used drugs in older people, such as digoxin.

\section{Naftidrofuryl oxalate and orphenadrine citrate}

Naftidrofuryl oxalate, a vasodilator, and orphenadrine citrate, an anticholinergic with muscle relaxant properties, have both been evaluated in small controlled trials. In a double blind, placebo controlled trial in 14 patients, naftidrofuryl oxalate, given as a slow release preparation $30 \mathrm{mg}$ twice a day, significantly reduced the frequency of cramp and increased the number of cramp-free days by a third. ${ }^{25}$ Orphenadrine citrate reduced the frequency of cramps by at least $30 \%$ in $90 \%$ of 59 patients with leg cramps in a double blind crossover trial. ${ }^{26}$

\section{Other treatments}

In an uncontrolled study of eight cramp sufferers refractory to quinine treatment, seven patients reported an improvement in their cramp symptoms on verapamil $120 \mathrm{mg}$ at night for eight weeks. ${ }^{27}$ Despite promising results in uncontrolled studies, a randomised controlled crossover trial showed that vitamin $\mathrm{E}$ does not reduce the frequency of cramps. ${ }^{28}$

\section{CONCLUSIONS}

Troublesome nocturnal leg cramps are common in older people. The pathophysiology of such cramps remains uncertain, but they are associated with many common diseases and medications. Identification of potentially treatable factors is important in patients with cramps. There have been no controlled trials examining the efficacy of physiological methods of preventing cramp. Nevertheless, such methods deserve a therapeutic trial given that a completely safe and effective pharmacological remedy remains elusive.

Quinine is moderately effective in preventing nocturnal leg cramps. However, there are significant concerns about the 
risk/benefit ratio with this drug. In patients with severe symptoms, a trial of 4-6 weeks' treatment with quinine is probably still justified, but patients should be warned of the risks, and the efficacy of treatment should be monitored, for example using a sleep and cramp diary. A trial of treatment with natridrofuryl or orphenadrine is a reasonable alternative, although further larger studies are needed to confirm the benefit with these agents. If patients do not respond to quinine, verapamil $120 \mathrm{mg}$ daily may be tried, although controlled data are still lacking.

\section{Authors' affiliations}

J V Butler, E C Mulkerrin, S T O'Keeffe, Department of Medicine for the Elderly, University College Hospital and Merlin Park Hospital, Galway, Ireland

\section{REFERENCES}

1 Naylor RJ, Young JB. A general population survey of leg cramps. Age Ageing 1994:23:418-20.

2 Abdulla AJ, Jones PW, Pearce VR. Leg cramps in the elderly: prevalence, drug and disease associations. Int J Clin Pract 1999;53:494-6

3 Sontag SJ, Wanner JN. The cause of leg cramps and knee pains: a hypothesis and effective treatment. Med Hypothesis 1988;25:35-41.

4 Criggs RC. Episodic muscle spasms, cramps, and weakness. In: Fauci AS, Braunwald E, Isselbaucher KJ, et al, eds. Harrison's principles of internal medicine. 14th Ed. New York: McGraw Hill International, 1998: 119.

5 Jansen PHP, Joosten EMG, Vingerhoets HM. Muscle cramp: main theories as to aetiology. Eur Arch Psychiatry Neurol Sci 1990;239:337-42

6 Morl H, Dieterich HA. Nocturnal leg cramps-their causes and treatment. Med Klin 1980;75:264-7.

7 Eaton JM. Is this really a muscle cramp? Postgrad Med J 1989;86:227-32.

8 McGee SR. Muscle cramps. Arch Intern Med 1990;150:511-18.

9 Haskell SG, Fiebach NH. Clinical epidemiology of nocturnal leg cramps in male veterans. Am J Med Sci 1997;313:210-4.

10 Mackie MA, Davidson J. Prescribing of quinine and cramp inducing drugs in general practice. BM 1995;311:1541.
11 Fowler AW. Relief of cramps. Lancet 1973;i:99.

12 Daniel HW. Simple cure for nocturnal leg cramps. N Engl J Med 1979;301:216

13 Warburton A, Royston JP, O'Neill CJA, et al. A quinine a day keeps the leg cramps away? Br J Clin Pharmacol 1987;23:459-65.

14 Webster LT. Drugs used in the chemotherapy of protozoal infections. Malaria. In: Goodman A, Gilman A, Rall TW, et al, eds. The pharmacological basis of therapeutics. Singapore: McGraw Hill, 1992.

15 Moss HK, Herrmann LG. Use of quinine for relief of "night cramps" in the extremities. JAMA 1940;115:1358-9.

16 Jansen PHP, Veenhuizen KCW, Wesseling ALM, et al. Randomised controlled trial of hydroxyquinine in muscle cramps. Lancet 1997:349:528-32.

17 Man-Son-Hing M, Wells G. Meta-analysis of efficacy of quinine for treatment of nocturnal leg cramps in elderly people. BM 1995;310:13-17.

18 Man-Son-Hing $M$, Wells $G$, Lau A. Quinine for nocturnal leg cramps: a mete-analysis including unpublished data. J Gen Intern Med 1998; 13:600-6.

19 Gorlich HD, Von Gablenz E, Steinberg HW. Treatment of nocturnal leg cramps. A multicentre, double blind, placebo controlled comparison between the combination of quinine and theophylline ethylene diamine with quinine. Arzneimittelforschung 1991;41:167-75.

20 US Department of Health and Human Services. Stop to marketing of quinine for night leg cramps. FDA Consumer (July-August) 1995;29:1-2.

21 US Department of Health and Human Services. Drug products for the treatment and /or prevention of nocturnal leg muscle cramps for over the counter human use. Federal Registrar 1994;59:43234-52.

22 Katz B, Weetch M, Chopra S. Quinine induced granulomatous hepatitis. BM 1983;286:264-5.

23 McDonald SP, Shanahan EM, Thomas AC, et al. Quinine induced haemolytic uraemic syndrome. Clin Nephrol 1997;47:397-400.

24 Fung MC, Halbrook JH. Placebo-controlled trial of quinine therapy for nocturnal leg cramps. West J Med 1989;151:42-4.

25 Young JB, Connolly M. Naftidrofuryl treatment for rest cramp. Postgrad Med J 1993;69:624-6.

26 Latta D, Turner E. An alternative to quinine in nocturnal leg cramps. Curr Ther Res 1989:45:833-7.

27 Baltodano N, Gallo BV, Weidler DJ. Verapamil vs quinine in recumbent nocturnal leg cramps in the elderly. Arch Intern Med 1988;148: 1969-70.

28 Connolly PS, Shirley EA, Wasson JH, et al. Treatment of nocturnal leg cramps: a crossover trial of quinine vs vitamin E. Arch Intern Med 1992;152:1877-8.

\section{New method relieves patients of urinary catheters}

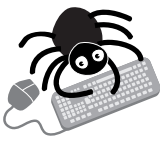

Please visit the Postgraduate Medical Journal website [www. postgradmedj.com for link to this full article.
Datients will undoubtedly be grateful that the problem of a non-deflating suprapubic urinary catheter can be overcome simply and safely with a newly described method. Two doctors in an accident and emergency department hit on the solution while trying to remove such a catheter from a bedbound woman after all other attempts at deflating the catheter had failed.

The method entailed gently pulling the catheter to bring the balloon close to the internal opening of the fistula tract. Next, an intravenous cannula (18 gauge) was taken, its cap and hub removed, and a $20 \mathrm{ml}$ syringe attached to the needle. The sheath was adjusted to cover the point of the needle, and this end was introduced down the fistula, close by the catheter wall until it met with a slight resistance. Then the tip of the needle was pushed through the end of the sheath, allowing the syringe to fill automatically with balloon fluid and the catheter to be removed easily. The method also worked when tested experimentally with catheters of 12-16 gauge.

Replacing this type of catheter is common practice in accident and emergency departments, but quite often the balloon does not deflate. Some other methods resort to tearing the balloon, but these may leave debris behind, whereas this method is safe and-best of all—quick.

A Emergency Medicine Journal 2002;19:354 